\title{
Substituição do xilol por óleo de coco extravirgem na etapa de diafanização da rotina
}

\section{histológica}

\author{
Sulbstitution of xylol by extra virgin coconut oil in the diaphanization stage of histological routine \\ Sustitución del xilol por aceite de coco extravirgen en la etapa de diafanización de la rutina \\ histológica
}

Recebido: 10/12/2021 | Revisado: 14/12/2021 | Aceito: 17/12/2021 | Publicado: 02/01/2022

\author{
Brenda Oliveira de Abreu \\ ORCID: https://orcid.org/0000-0002-2543-7167 \\ Universidade de Pernambuco, Brasil \\ E-mail: brenda.o.abreu@gmail.com \\ Inalda Maria de Oliveira Messias \\ ORCID: https://orcid.org/0000-0001-8699-3717 \\ Universidade de Pernambuco, Brasil \\ E-mail: inalda.messias@upe.br \\ Rosane Jamille de Oliveira Araújo \\ ORCID: https://orcid.org/0000-0002-6462-2541 \\ Universidade Federal Rural de Pernambuco, Brasil \\ E-mail: jamille.rosane@gmail.com \\ Mônica Simões Florêncio \\ ORCID: https://orcid.org/0000-0002-8548-1725 \\ Universidade de Pernambuco, Brasil \\ E-mail: monica.simoes@upe.br \\ João Ferreira da Silva Filho \\ ORCID: https://orcid.org/0000-0002-2527-8864 \\ Universidade de Pernambuco, Brasil \\ E-mail: joao.filho@upe.br \\ Júlio Brando Messias \\ ORCID: https://orcid.org/0000-0001-6996-974X \\ Universidade de Pernambuco, Brasil \\ E-mail: julio.messias@upe.br
}

\begin{abstract}
Resumo
O xilol é um composto utilizado no processamento histológico, na etapa de diafanização, sendo um solvente nocivo à saúde coletiva e ao meio ambiente. O objetivo desse estudo foi apresentar uma metodologia alternativa ao uso do xilol, na etapa de diafanização da rotina histológica utilizando o óleo de coco extravirgem. Foram utilizados fragmentos de orelha, cerebelo e língua de Rattus norvegicus divididos em cinco grupos. O grupo controle, diafanizado com xilol, o grupo tratado I, com xilol e 30\% de óleo de coco, o tratado II com xilol e 50\% óleo de coco, o tratado III com xilol e 70\% óleo de coco e o tratado IV apenas com óleo de coco. Lâminas de todos os grupos e tecidos foram coradas com Hematoxilina de Harris e Eosina, as lâminas de cerebelo também foram coradas com Hematoxilina Fosfotúngstica e Eosina, as de língua pelo método Tricrômico de Gomori e as de orelha por Orceína com Hematoxilina de Harris. Os tecidos avaliados não apresentaram diferenças entre os grupos no processo de diafanização, emblocamento e coloração, a ação diafanizante do óleo manteve a morfologia dos tecidos e não causou interferência nas colorações. Podemos concluir que o óleo de coco é um substituto promissor ao uso do xilol na etapa de diafanização, sendo uma alternativa mais segura e de baixo custo, não comprometendo a morfologia dos tecidos e sem interferir nas diferentes colorações utilizadas, além de minimizar os riscos à saúde pública e ambiental.
\end{abstract}

Palavras-chave: Estruturas animais; Histologia; Técnicas histológicas; Cocos nucifera; Rattus norvegicus.

\begin{abstract}
Xylol is a compound used in histological processing, in the diaphanization step, and is a harmful solvent to public health and the environment. The aim of the study was to present an alternative methodology to the use of xylol, in the clearing stage of the histological routine I use extra virgin coconut oil. Rattus norvegicus ear, cerebellum and tongue fragments divided into five groups were used. The control group, cleared with xylol, the treated group I, with xylol and 30\% coconut oil, the treated II with xylol and 50\% coconut oil, the treated III with xylol and $70 \%$ coconut oil and the treated IV just with coconut oil. Slides from all groups and tissues were stained with Harris Hematoxylin and Eosin, as cerebellum slides were also stained with Phosphotungstic Hematoxylin and Eosin, as for tongue by Gomori's Trichrome and as ear by Orcein with Harris' Hematoxylin. Tissues derived not differentiated between groups in the process of diaphanization, blocking and staining, the clearing action of the oil maintained the tissue morphology and
\end{abstract}


did not interfere with staining. We can demand that coconut oil is a promising substitute for the use of xylol in the diaphanization step, being a safer and low-cost alternative, without compromising tissue morphology and without interfering with the different colors used, in addition to minimizing the risks to public and environmental health.

Keywords: Animal structures; Histology; Histological techniques; Cocos nucifera; Rattus norvegicus.

\section{Resumen}

El xilol es un compuesto utilizado en el proceso histológico, en la etapa de diafanización, siendo un solvente nocivo para la salud colectiva y el medio ambiente. El objetivo de este estudio fue presentar una metodología alternativa al uso del xilol, en la etapa de diafanización de la rutina histológica utilizando el aceite de coco extravirgen. Fueron utilizados fragmentos de oreja, cerebelo y lengua de Rattus norvegicus divididos en cinco grupos. El grupo control diafanizado con xilol, el grupo I tratado con xilol y $30 \%$ de aceite de coco, el grupo II tratado con xilol y $50 \%$ aceite de coco, el grupo III tratado con xilol y $70 \%$ aceite de coco y el grupo IV tratado sólo con aceite de coco. Láminas de todos los grupos y tejidos fueron coloreadas con Hematoxilina de Harris y Eosina, las láminas de cerebelo además fueron coloreadas con Hematoxilina Fosfotúngstica y eosina, las de lengua por el método Tricrómico de Gomori y las de oreja por Orceína con Hematoxilina de Harris. Los tejidos evaluados no presentaron diferencias entre los grupos en el proceso de diafanización, solidificación y coloración, la acción diafanizante del aceite mantuvo la morfología de los tejidos y no causó interferencia en las coloraciones. Podemos concluir que el aceite de coco es un potencial sustituto al uso del xilol en la etapa de diafanización. Siendo una alternativa más segura y de menor costo, que no compromete la morfología de los tejidos y no interfiere en las diferentes coloraciones utilizadas y además minimiza los riesgos para la salud pública y ambiental.

Palabras clave: Animal structures; Histology; Histological techniques; Cocos nucifera; Rattus norvegicus.

\section{Introdução}

Amostras teciduais que devem ser submetidas a exames histológico ou histopatológicos, quando se opta por um método com parafina, precisam passar por uma sequência de procedimentos cujo objetivo é garantir que o fragmento possa ser estudado e na rotina histológica, um tecido mole para se tornar uma lâmina e ser observado em microscopia ótica, passa por várias fases, que vai desde a sua coleta e fixação, passando pela desidratação, diafanização (clarificação), impregnação (inclusão em parafina), microtomia, desparafinização, coloração e montagem, estas etapas conferem suporte ao tecido, além de possibilitar a sua visualização ao microscópio. Neste contexto o xilol é utilizado nas etapas de diafanização, na desparafinação e montagem final das lâminas (Bancroft \& Gamble, 2008; Mohammedsaleh, 2014; Patraquim, 2015; Camillo et al., 2017; Do Nascimento et al., 2020), os protocolos dessas etapas dependem ainda do espécime biológico, do tipo de tecido entre outros fatores (Souza et al., 2010).

O xilol ou xileno é um composto aromático derivado do petróleo que compõe o grupo BTEX (benzeno, tolueno, etilbenzeno e xilenos) de Compostos Orgânicos Voláteis (COV) assim como benzeno, tolueno e etilbenzeno. Seus isômeros (orto, meta e para), são solventes, usados em tintas, vernizes, borracha, tinturas, corantes, preparo farmacêuticos, indústrias de plásticos e de petróleo, na fabricação de alguns ácidos e solventes em análises de laboratório (Costa et al., 2007; Cetesb, 2016; Hernandes et al., 2017).

O uso de equipamentos de proteção é necessário, quando se trata de xilol, visto que pode trazer danos à saúde relacionados ao tempo e a concentração resultante da exposição desse composto. Irritação dos olhos, das mucosas e da pele, desconforto gástrico e dores de cabeça são os relatos mais comuns da exposição excessiva do solvente (United States, 2007; Cetesb, 2016; Hernandes et al., 2017; Cetesb, 2021). O Conama (Conselho Nacional de Meio Ambiente), classifica o resíduo de xilol no Grupo B, ou seja, que apresenta risco a saúde pública e ao meio ambiente (Brasil, 2005). Resíduo de xilol deve ser incinerador quimicamente (Cetesb, 2021) ou, se for proveniente de laboratório de histologia e/ou patologia, pode ser reaproveitado através de uma destilação fracionada em cerca de 70\% (Schwarz, 2017).

Existem vários relatos na literatura de óleos vegetais como substitutos do xilol na rotina histológica, Rasmussen et al. (1992) utilizaram óleo de oliva (azeite) na etapa de diafanização e o óleo de coco na etapa de impregnação e não os consideraram, menos adequado para o diagnóstico histológico, quando comparados ao xilol. Udonkang et al. (2014) avaliaram o óleo de palma como clarificante e constataram pequenas diferenças em relação ao xilol, sem comprometer, a qualidade dos 
tecidos; Sermadi et al. (2014) compararam o óleo de coco com o xilol como clarificante e não evidenciaram comprometimento da qualidade histológica; Indu et al. (2014) propuseram o óleo de cedro como uma alternativa eficaz, ecológica e segura ao xileno como agente de desparafinixação no laboratório histopatológico; Swamy et al. (2015) utilizaram com sucesso, óleo de cenoura, óleo de pinho, óleo de rosa e óleo de oliva (azeite) no processamento histológico, e constataram que os quatro óleos apresentam capacidade de diafanizar os tecidos semelhante ao xilol, sendo óleos econômicos e que não comprometem a coloração histológica; o óleo de pinho foi superior em suas propriedades físicas e de clareamento; Digala et al. (2017) relatam que os resultados obtidos com o óleo de coco e o óleo de amendoim são melhores do que o xilol no processamento de tecidos sem riscos a saúde; Ashitha (2018) utilizou óleo de coco e óleo de palma na etapa de diafanização e constatou que ambos os óleos, com vantagem para o de coco, apresentam potencial como substituto do xilol; Chandraker et al. (2018) reportaram dificuldades substituindo o xilol por óleo de coco, mas afirmaram que a qualidade histológica é semelhante e sem risco a saúde; Ravindran et al. (2018) avaliaram o óleo palma e constaram semelhança com o xilol, com bons resultados histológicos, sendo produto isento de toxicidade, sem riscos, não inflamável, biodegradável, econômico, de fácil manuseio e prontamente disponível, além das características de coloração com coloração hematoxilina e eosina (H/E) mostrarem longevidade sem desbotamento.

Recentemente, Sermadi et al. (2019) usaram o azeite na etapa de clarificação, sem relatarem diferenças ao uso do xileno; o óleo de rícino foi proposto por Carreira et al. (2019) como um bom substituto do xilol no processamento de histológico de diafanização, tendo em vista os resultados obtidos em seu estudo; Abreu et al. (2019) demonstraram que na etapa de diafanização, a solução 1:1 (xilol e óleo de coco) era satisfatória e atende as especificidades da rotina histológica; Akpulu et al. (2021) recomendaram o óleo de eucalipto como agente eficaz no processo de desparafinação sem comprometimento na etapa de coloração e Tsamiya et al. (2021) afirmaram que o azeite, óleo de cravo e óleo de amendoim têm capacidade para diafanizar os tecidos quando comparados com aqueles clarificados com xileno, considerando ainda seu custo reduzido, disponibilidade, efeitos benéficos à saúde e segurança ao meio ambiente.

O coco da baía ou simplesmente coco é o fruto do coqueiro (Cocos nucifera L.) é a única espécie do gênero, uma das mais importantes famílias da classe Monocotyledoneae. É uma angiosperma monocotiledônea da família Arecaceae. O fruto possui uma epiderme lisa ou epicarpo externo, um mesocarpo intermediário espesso e fibroso, e um endocarpo interno com um albume branco sólido e um albúmen líquido (Cuenca et al., 2021; Lima, 2015). A cocoicultura é um setor que tem uma grande importância socioeconômica, visto que gera uma gama de empregos diretos e indiretos, e isso se deve versatilidade de todos os componentes da árvore e principalmente do fruto. O óleo é um desses produtos do coco extraído do albume branco sólido, sendo a principal fonte de ácido láurico para a indústria (Embrapa, 2019). O óleo de coco é empregado na produção de alimentos, sabões, cosméticos e na fabricação de biopolímeros e biodiesel (Araújo et al., 2009; Carpiné, 2015; Bressan et al., 2017).

Por ser um composto extremamente volátil, o xilol requer das pessoas envolvidas com o seu uso conhecimento dos seus riscos, das formas de prevenção, descarte e da necessidade de equipamentos de proteção individual e coletivos, e neste contexto pesquisas sobre meios de substituição total ou parcial do xilol tornam-se necessárias. Assim, o óleo de coco pode ser uma alternativa de baixo custo e não tóxica para substituição do xilol na rotina histológica. O óleo de coco é facilmente encontrado no comércio e sem histórico relevante de toxidade para a população. É um produto de origem vegetal, que possui uma cadeia produtiva ampla e presente em várias regiões do país, utilizado na alimentação humana e animal, explorado como alternativa para outros compostos derivados do petróleo, como a cera. O objetivo desse estudo foi apresentar uma metodologia alternativa na rotina histológica, de reduzido custo e risco biológico para o processo de diafanização, utilizando o óleo de coco extravirgem. 


\section{Metodologia}

Trata-se de um estudo bibliográfico e experimental (Gil, 2017), que teve como objeto de estudo uma alternativa para substituir o xilol na rotina histológica. O estudo foi desenvolvido no Laboratório de Técnicas Histológicas e Embriológicas do Instituto de Ciências Biológicas da Universidade de Pernambuco, no Campus Santo Amaro, Recife (PE).

Para a realização deste trabalho foram utilizados cinco fragmentos de diferentes tecidos de Rattus norvegicus (cerebelo, língua e orelha), previamente fixados em formol tamponado a 10\% e mantidos (conservados) em álcool a $70 \%$.

O processamento histológico experimental, consistiu nas etapas de:

1. Desidratação: Os fragmentos (controle e tratados), conservados em álcool a 70\%, passaram por protocolos semelhantes de desidratação em álcool de 1 hora [Álcool 90\%, 100\% (I) e 100\% (II)], diferenciando na etapa de diafanização.

2. Diafanização: Os fragmentos foram distribuídos em cinco grupos de acordo com uma adaptação da pesquisa realizada por Ofusori et al. (2009). O grupo controle teve os fragmentos submetidos pelo tratamento histológico rotineiro, utilizando dois banhos de 1 hora em xilol (temperatura ambiente), enquanto os grupos tratados foram submetidos a dois banhos de 1 hora (temperatura ambiente) dos seguintes protocolos: tratamento I - 70\% xilol e 30\% óleo de coco; tratamento II - 50\% xilol e 50\% óleo de coco; tratamento III - 30\% xilol e 70\% óleo de coco; tratamento IV - 100\% óleo de coco.

3. Impregnação e Confecção dos blocos de parafina: Os tecidos dos grupos (controle e tratados) sofreram dois banhos em parafina de 1h:00 e de 30m em parafina/cera de abelha a 65oC (Do Nascimento et al., 2020), em seguida foram confeccionados os blocos em parafina líquida em forma de silicone, etiquetados e levados para resfriar.

4. Microtomia: Os blocos (controle e tratados) foram cortados em $5 \mu \mathrm{m}$ utilizando o micrômetro Leica® RM2165. Em seguida as lâminas foram identificadas, e colocadas para secar em estufa a 60oC por 25 minutos e armazenadas.

5. Colorações: Os órgãos (cerebelo, língua e orelha) dos grupos controle e tratados foram corados com a técnica de Hematoxilina de Harris com Eosina (H/E). Lâminas de orelha foram corados em Orceína e Hematoxilina de Harris, preparações de língua foram corados pelo método Tricrômico de Gomori e lâminas de cerebelo foram corados por Hematoxilina Fosfotúngstica e Eosina. Para serem coradas todas as lâminas foram desparafinadas de forma rotineira com xilol e submetidas ao processo de coloração (Tolosa et al., 2003).

6. Montagem: A fase final do processamento histológico seguiu a metodologia proposta por Cazari et al. (2013) com modificações, que consistiu em submeter as lâminas em estufa a 65oC por 10 minutos para secagem e montagem com lamínula em Entellan®.

A análise e registro das imagens foram realizadas utilizando o microscópio Olympus® CX31 e as imagens obtidas através da câmera fotográfica do mesmo fabricante. Os órgãos utilizados neste estudo tiveram a aprovação prévia do Comitê de Ética em uso com animais, da Universidade de Pernambuco / UPE (CEUA: 02/14).

\section{Resultados e Discussão}

Os diferentes tecidos avaliados (orelha, língua e cerebelo) não apresentaram diferenças, independentemente do tratamento empregado (T-I a T-IV) no processo de diafanização, impregnação, emblocamento e coloração. Sendo demonstrado que o óleo de coco associado ou puro é um bom substituto para o xilol na etapa de diafanização.

A Figura 1 e 2 apresentam cortes de orelha corados com H/E e Orceína com Hematoxilina de Harris, respectivamente. Em todas as lâminas é possível identificar as mesmas estruturas histológicas, tecido conjuntivo e tecido cartilaginoso. Na coloração empregada na Figura 2 as fibras elásticas são evidenciadas.

Na Figura 3 e 4 observam-se cortes de língua corados com H/E e Tricrômico de Gomori, respectivamente. É possível identificar nas lâminas histológicas tecido adiposo, fibras musculares estriadas e nervos periféricos.

A Figura 5 e 6 trazem cortes de cerebelo corados com H/E e Hematoxilina Fosfotúngstica com Eosina, 
Research, Society and Development, v. 11, n. 1, e5911124609, 2022

(CC BY 4.0) | ISSN 2525-3409 | DOI: http://dx.doi.org/10.33448/rsd-v11i1.24609

respectivamente. As estruturas evidenciadas nos cortes são a meninge, camada molecular, células de Purkinje, camada granulosa e substância branca.

Figura 1: Orelha (Hematoxilina e Eosina - H/E)
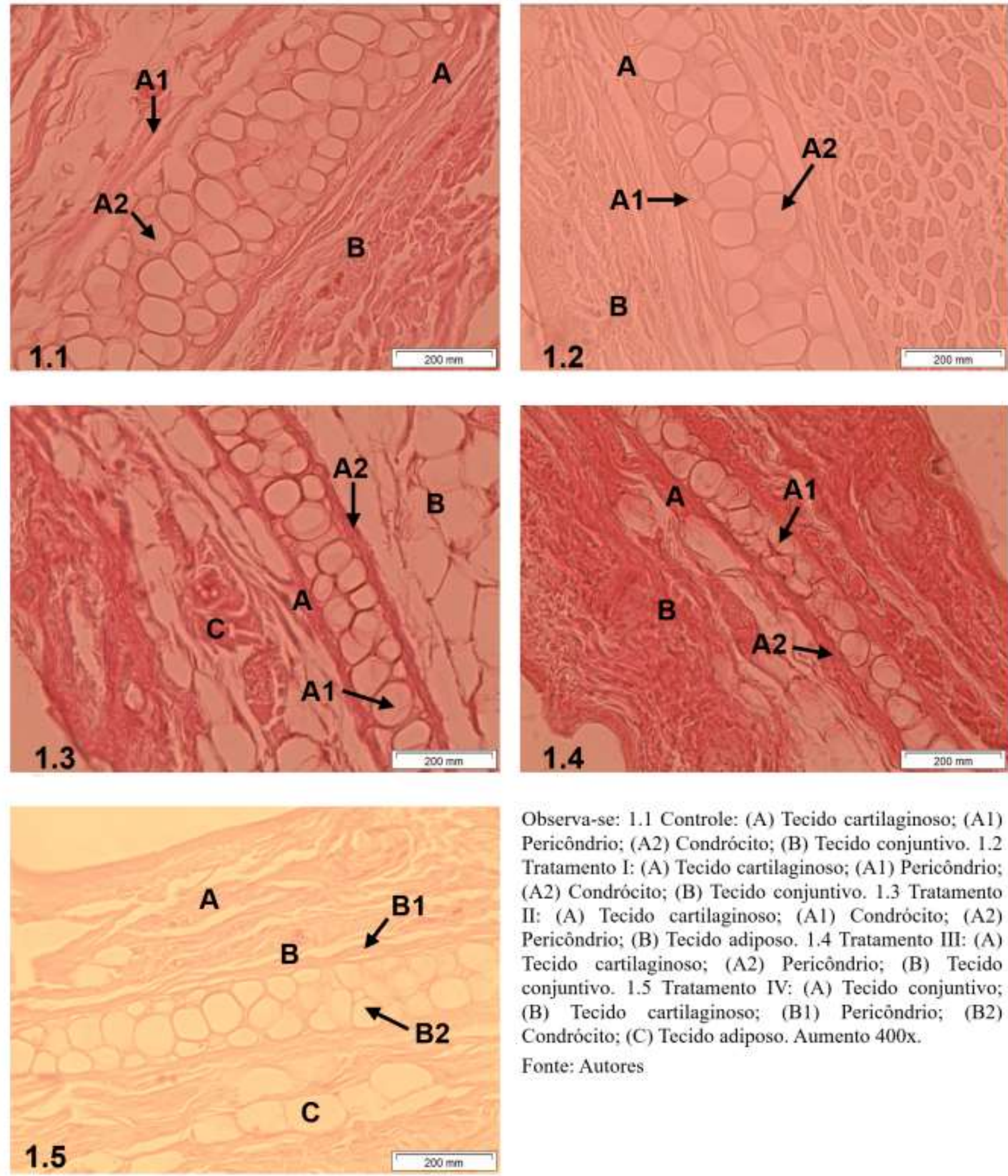

Observa-se: 1.1 Controle: (A) Tecido cartilaginoso; (Al) Pericondrio; (A2) Condrócito; (B) Tecido conjuntivo. 1.2 Tratamento I: (A) Tecido cartilaginoso; (A1) Pericôndrio; (A2) Condrócito; (B) Tecido conjuntivo. 1.3 Tratamento II: (A) Tecido cartilaginoso; (A1) Condrócito; (A2) Pericôndrio; (B) Tecido adiposo. 1.4 Tratamento III: (A) Tecido cartilaginoso; (A2) Pericôndrio; (B) Tecido conjuntivo. 1.5 Tratamento IV: (A) Tecido conjuntivo; (B) Tecido cartilaginoso; (B1) Pericỏndrio; (B2) Condrócito: (C) Tecido adiposo. Aumento 400x.

Fonte: Autores 
Figura 2: Orelha (Orceina e Hematoxilina de Harris)
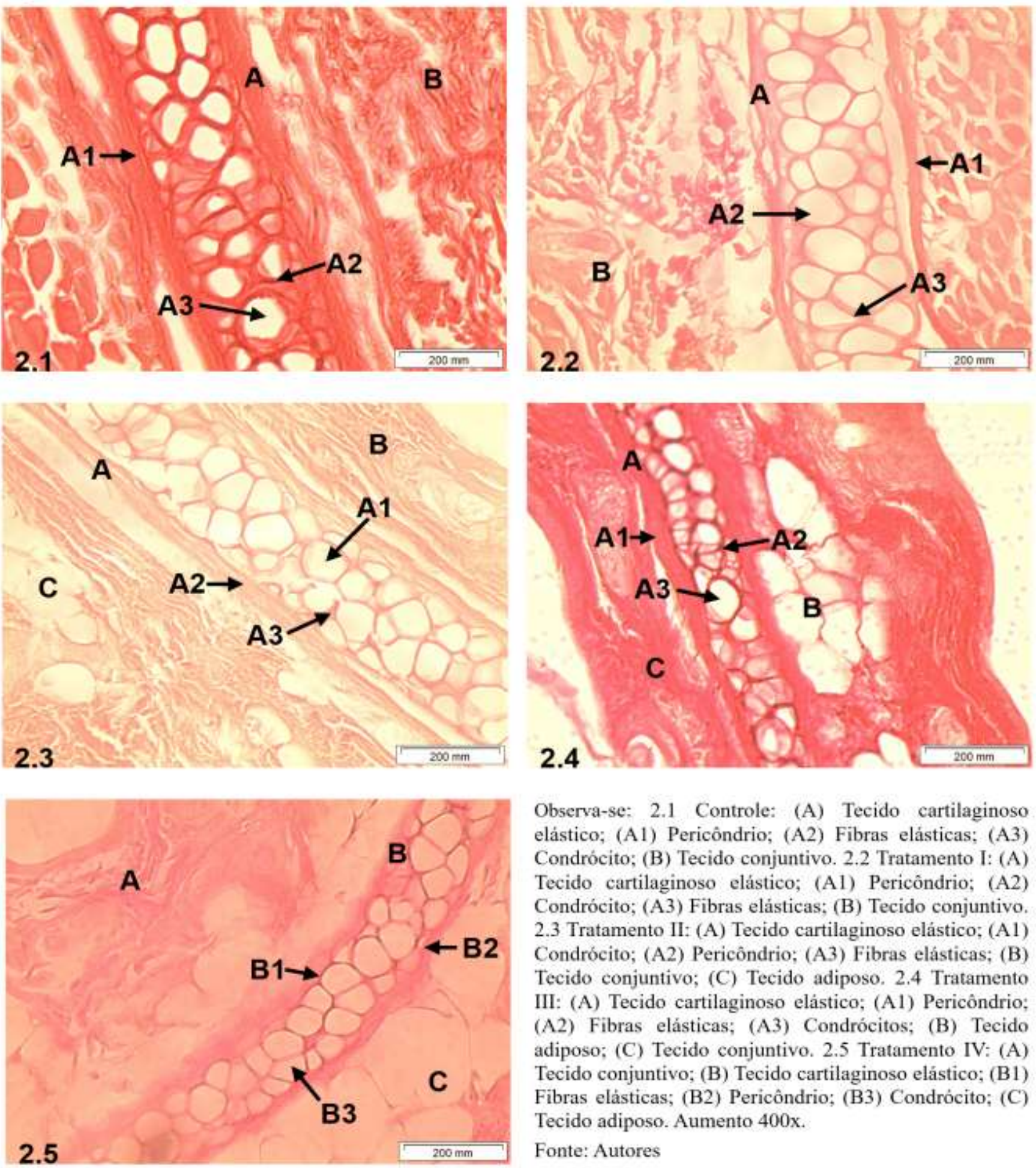

Observa-se: 2.1 Controle: (A) Tecido cartilaginoso elástico; (A1) Pericôndrio; (A2) Fibras elásticas; (A3) Condrócito; (B) Tecido conjuntivo. 2.2 Tratamento I: (A) Tecido cartilaginoso elástico; (A1) Pericôndrio; (A2) Condrócito; (A3) Fibras elásticas; (B) Tecido conjuntivo. 2.3 Tratamento II: (A) Tecido cartilaginoso elástico; (A1) Condrócito; (A2) Pericôndrio; (A3) Fibras elásticas; (B) Tecido conjuntivo; (C) Tecido adiposo. 2.4 Tratamento III: (A) Tecido cartilaginoso elástico; (A1) Pericôndrio; (A2) Fibras elásticas; (A3) Condrócitos; (B) Tecido adiposo; (C) Tecido conjuntivo. 2.5 Tratamento IV: (A) Tecido conjuntivo; (B) Tecido cartilaginoso elástico; (B1) Fibras elásticas; (B2) Pericôndrio; (B3) Condrócito; (C) Tecido adiposo. Aumento $400 \mathrm{x}$.

Fonte: Autores 
Research, Society and Development, v. 11, n. 1, e5911124609, 2022

(CC BY 4.0) | ISSN 2525-3409 | DOI: http://dx.doi.org/10.33448/rsd-v11i1.24609

Figura 3: Língua (Hematoxilina e Eosina - H/E)
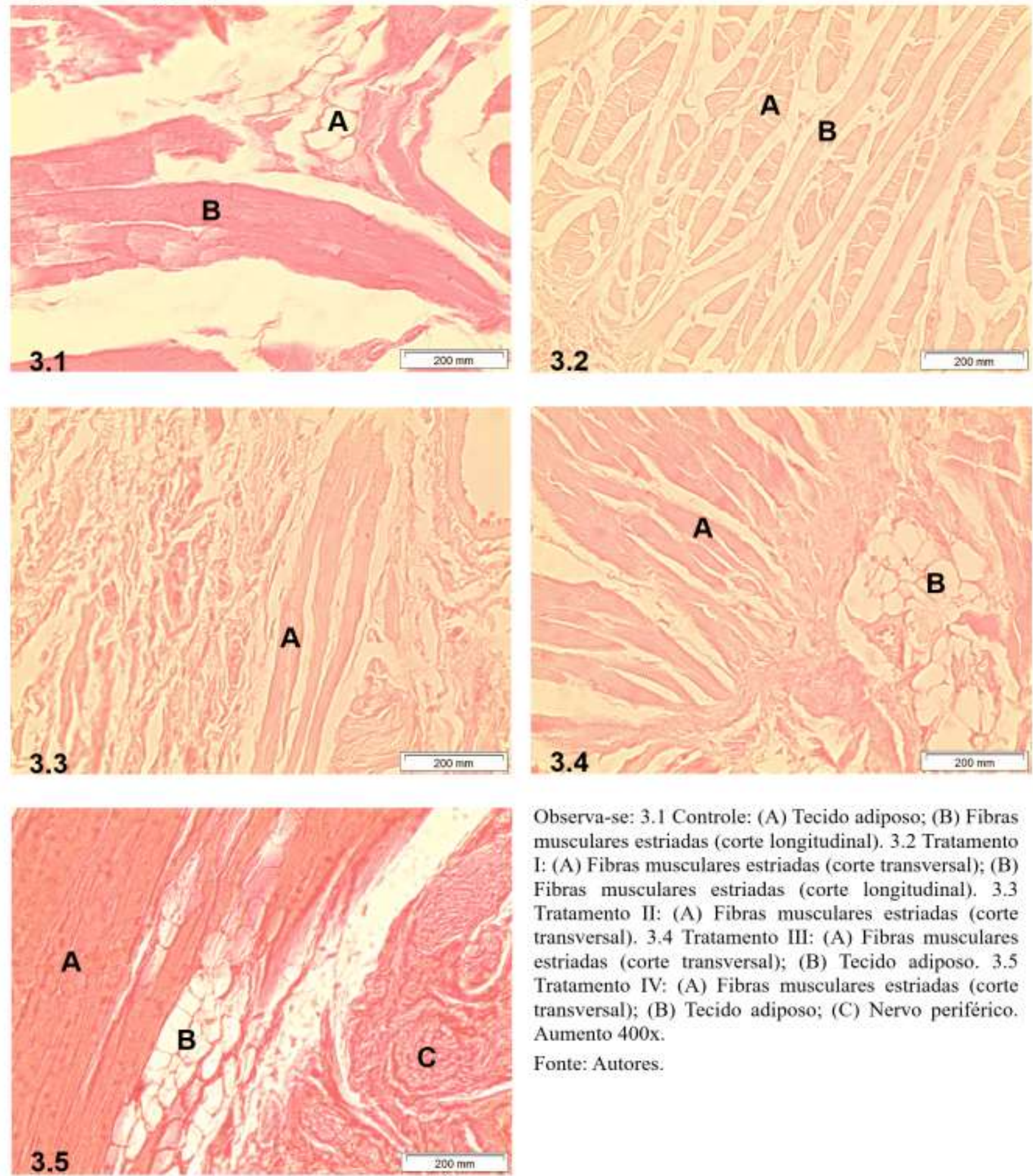

Observa-se: 3.1 Controle: (A) Tecido adiposo; (B) Fibras musculares estriadas (corte longitudinal). 3.2 Tratamento I: (A) Fibras musculares estriadas (corte transversal); (B) Fibras musculares estriadas (corte longitudinal). 3.3 Tratamento II: (A) Fibras musculares estriadas (corte transversal), 3.4 Tratamento III: (A) Fibras musculares estriadas (corte transversal); (B) Tecido adiposo. 3.5 Tratamento IV: (A) Fibras musculares estriadas (corte transversal); (B) Tecido adiposo; (C) Nervo periférico. Aumento 400x:

Fonte: Autores. 
Research, Society and Development, v. 11, n. 1, e5911124609, 2022

(CC BY 4.0) | ISSN 2525-3409 | DOI: http://dx.doi.org/10.33448/rsd-v11i1.24609

Figura 4: Língua (Tricrômico de Gomori)
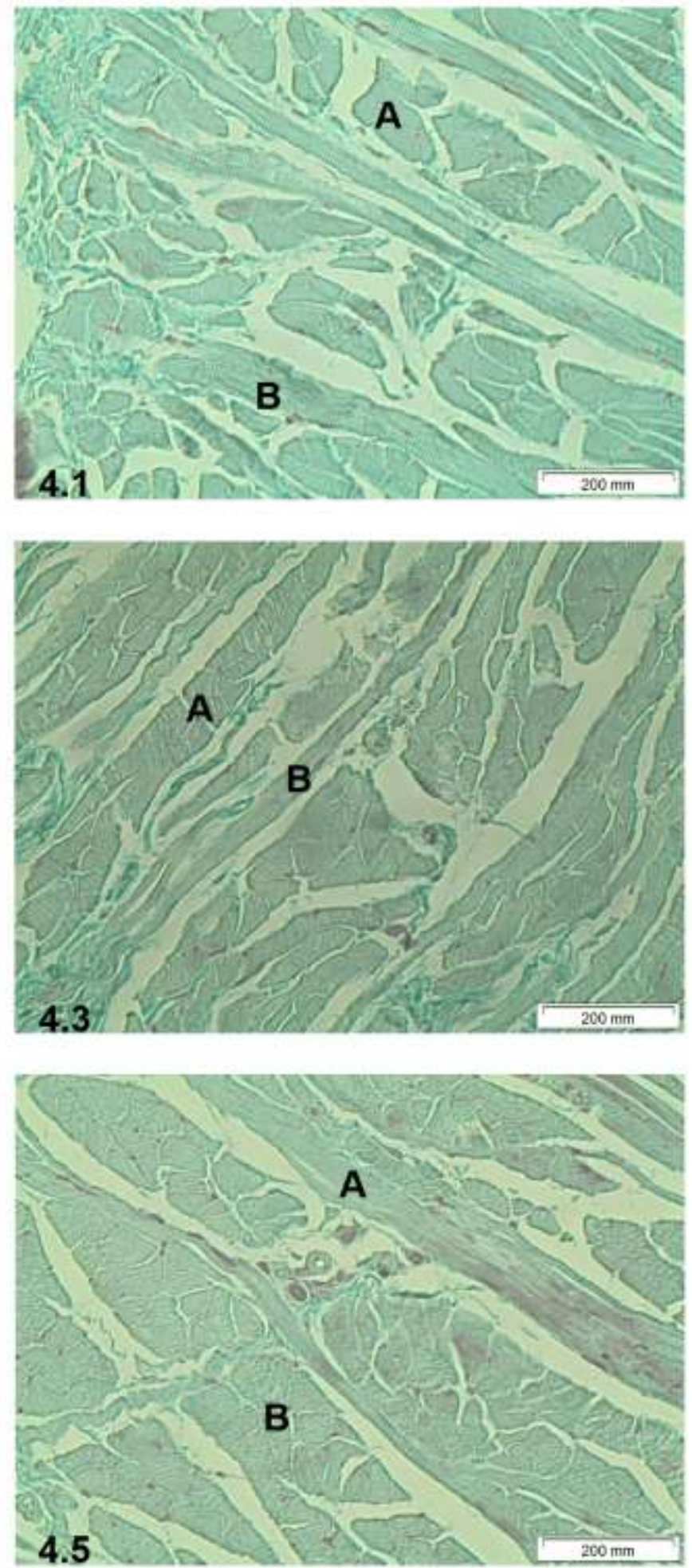
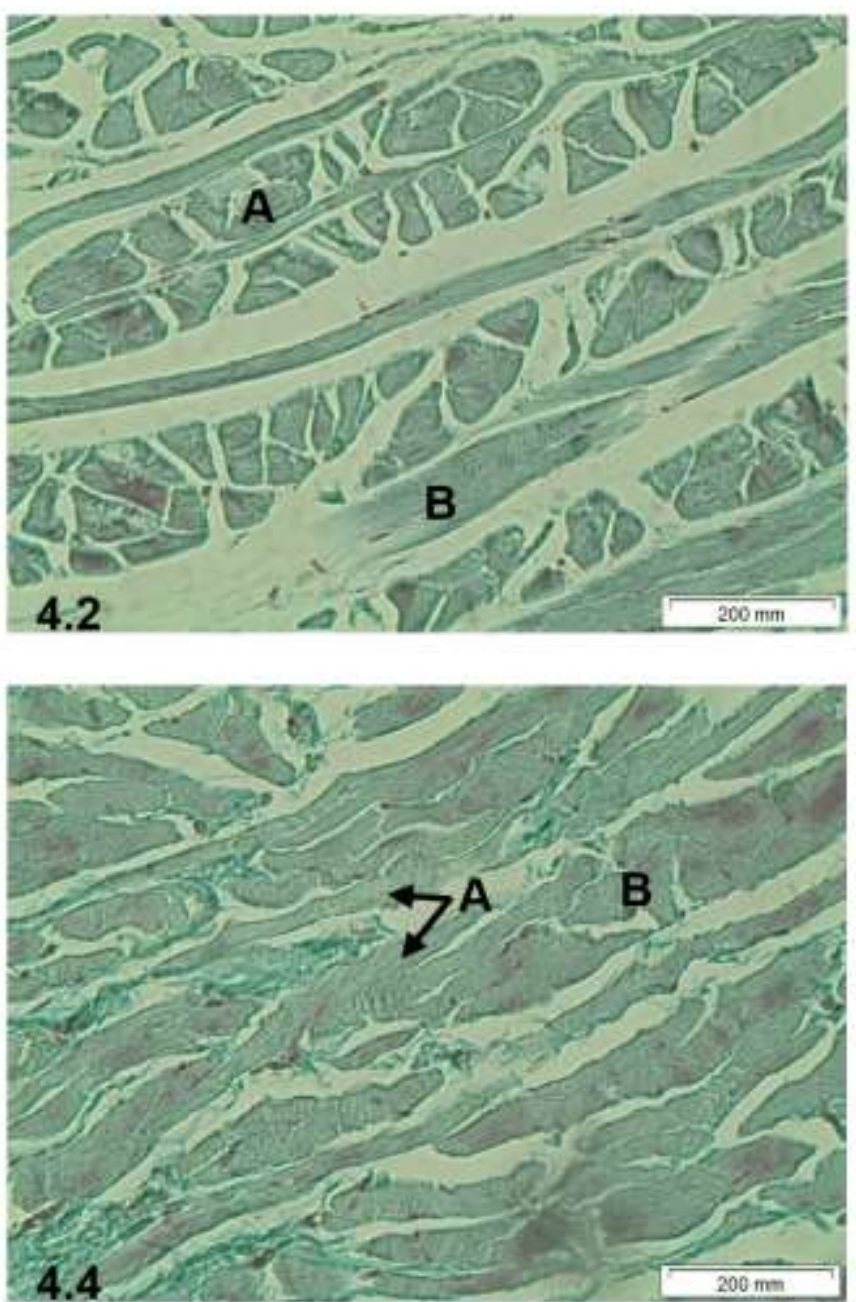

Observa-se; 4.1 Controle: (A) Fibras musculares estriadas (corte transversal); (B) Fibras musculares estriadas (corte longitudinal). 4.2 Tratamento I: (A) Fibras musculares estriadas (corte transversal); (B) Fibras musculares estriadas (corte longitudinal). 4.3 Tratamento II: (A) Fibras musculares estriadas (corte transversal). 4,4 Tratamento III: (A) Fibras musculares estriadas (corte longitudinal); (B) Fibras musculares estriadas (corte longitudinal); (B) Fibras musculares estriadas (corte transversal), 4.5 Tratamento IV: (A) Fibras musculares estriadas (corte longitudinal); (B) Fibras musculares estriadas (corte transversal). Aumento $400 \mathrm{x}$.

Fonte: Autores. 
Figura 5: Cerebelo (Hematoxilina e Eosina - H/E)
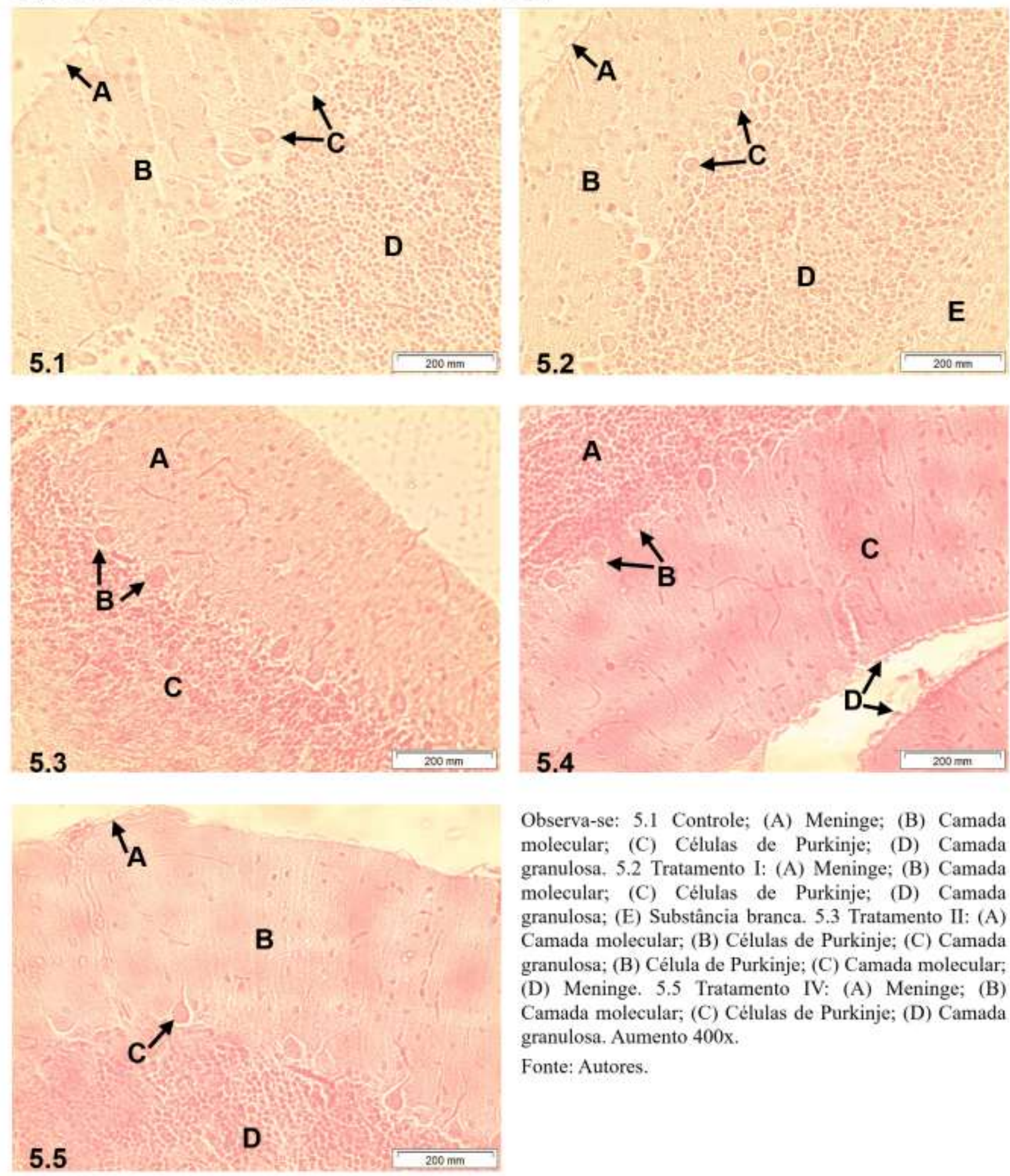

Observa-se: 5.1 Controle; (A) Meninge; (B) Camada molecular; (C) Células de Purkinje; (D) Camada granulosa, 5.2 Tratamento I: (A) Meninge; (B) Camada molecular; (C) Células de Purkinje; (D) Camada granulosa; (E) Substância branca. 5.3 Tratamento II: (A) Camada molecular; (B) Células de Purkinje; (C) Camada granulosa; (B) Célula de Purkinje; (C) Camada molecular; (D) Meninge. 5.5 Tratamento IV: (A) Meninge; (B) Camada molecular; (C) Células de Purkinje; (D) Camada granulosa. Aumento $400 \mathrm{x}$.

Fonte: Autores. 
Research, Society and Development, v. 11, n. 1, e5911124609, 2022

(CC BY 4.0) | ISSN 2525-3409 | DOI: http://dx.doi.org/10.33448/rsd-v11i1.24609

Figura 6: Cerebelo (Hematoxilina Fosfotúngstica e Eosina)
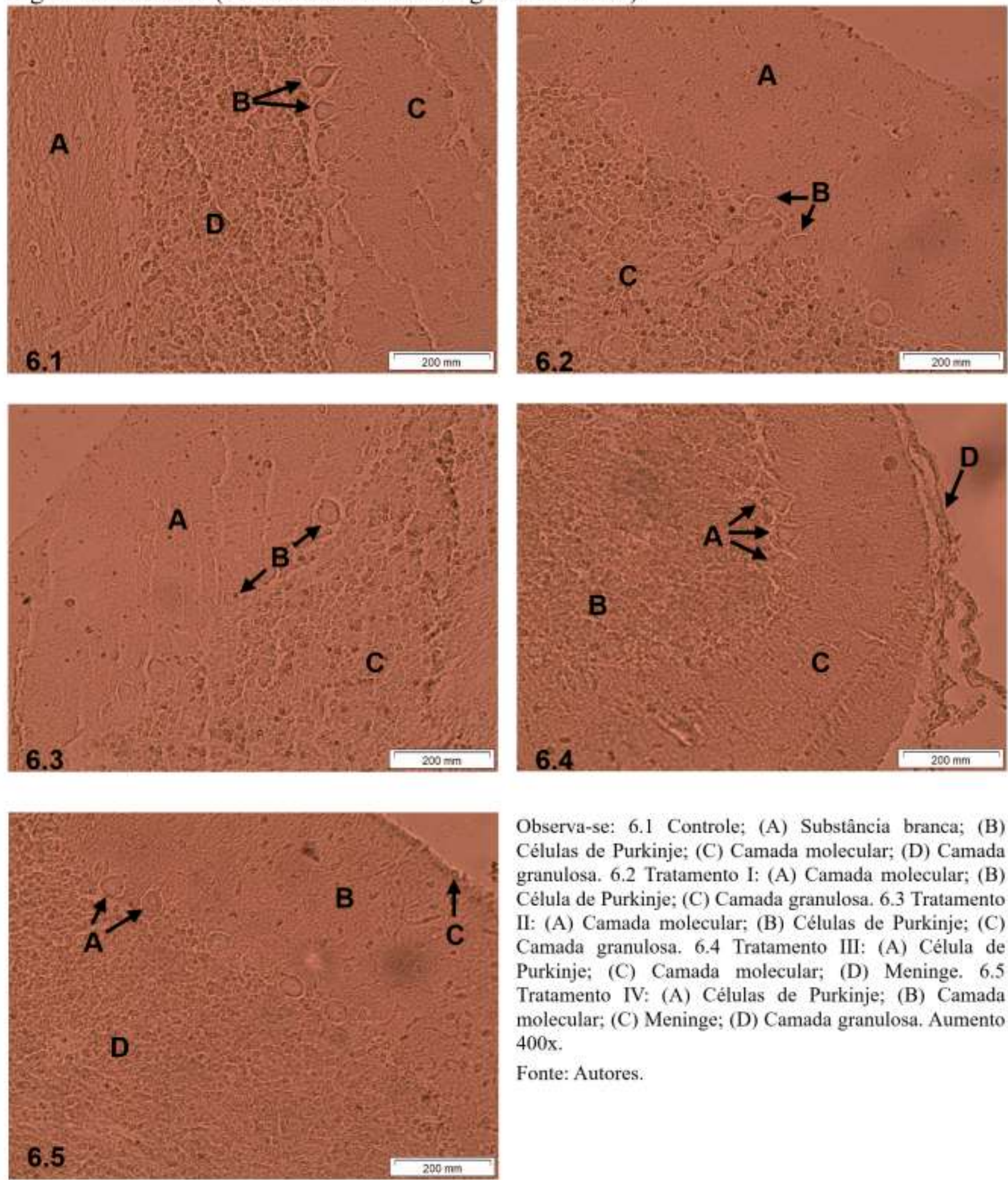

Observa-se: 6.1 Controle; (A) Substância branca; (B) Células de Purkinje; (C) Camada molecular; (D) Camada granulosa. 6.2 Tratamento I: (A) Camada molecular; (B) Célula de Purkinje; (C) Camada granulosa. 6.3 Tratamento II: (A) Camada molecular; (B) Células de Purkinje; (C) Camada granulosa. 6.4 Tratamento III: (A) Célula de Purkinje; (C) Camada molecular; (D) Meninge. 6.5 Tratamento IV: (A) Células de Purkinje; (B) Camada molecular; (C) Meninge; (D) Camada granulosa. Aumento $400 \mathrm{x}$.

Fonte: Autores. 
Após o processo de fixação e/ou conservação, a próxima etapa do processamento histológico, é a desidratação, tendo em vista que a substância utilizada antes da inclusão na parafina, não se homogeneíza com a água existente nos tecidos. O álcool etílico é comumente utilizado em proporções crescentes até o álcool absoluto (Timm, 2005; Camillo et al., 2017; Moreti et al., 2019; Do Nascimento et al., 2020). O uso alternativo do óleo de coco substituindo o xilol não interferiu no processo de clarificação e manteve as estruturas histológicas dos tecidos. A diafanização é a etapa do processamento histológico onde a peça previamente desidratada tem seu agente desidratante substituído por uma substância que possui afinidade com a parafina, possibilitando sua penetração no tecido. Nessa etapa também ocorre o clareamento do tecido, motivo pelo qual ela também é chamada clarificação (Nunes \& Cinsa, 2016). Além do xilol, as substâncias usadas rotineiramente na histológica, são o toluol, benzeno, óleo de cedro e os solventes universais, como acetato butílico, benzoato metílico e dióxido dietileno (Michalant, 1988; Tolosa et al., 2003; Ofusori et al., 2009; De Souza Junior, 2010; Piculo et al., 2014; Nunes \& Cinsa, 2016; Gartner \& Hiatt, 2017), outros agentes foram relatados como capazes de substituírem o xilol, como querosene, clorofórmio, salicilato de metila, hidrocarbonetos alifáticos de cadeia longa (Tolosa et al., 2003; Ofusori et al., 2009; Nunes; Cinsa, 2016).

Uma característica da fase de diafanização ou clarificação em órgãos submetidos ao xilol é a aparência translúcida dos tecidos expostos ao solvente (Tolosa et al., 2003; Timm, 2005, Nunes \& Cinsa, 2016). Os fragmentos de língua, orelha e cerebelo, utilizados em nosso estudo foram diafanizados de forma rotineiramente usando xilol, óleo de coco puro e óleo de coco em associação com xilol em temperatura ambiente. Essa metodologia fez com que os órgãos não ficassem totalmente translúcidos. Isso pode estar relacionado, ao ponto de fusão do óleo de coco, que de acordo com Martins e Santos é em torno de $\left(24,4-25,6^{\circ} \mathrm{C}\right)$, enquanto o do xilol é cerca de 13,3 oC (Cetesb, 2021).

De acordo com Chandraker et al. (2018) os tecidos processados com óleo de coco apresentaram menor translucidez e menor rigidez, quando comparado ao xilol, a pouca translucidez foi uma característica dos tecidos tratados com óleo de coco, enquanto a rigidez dos tecidos foi semelhante aos tecidos tratados com xilol. Essas dificuldades não foram relatadas por Sermadi et al. (2014) e Chandraker et al. (2018) que usaram apenas óleo de coco, Rasmussen et al. (1992) que testaram óleo de oliva e de coco, Digala et al. (2017) que testaram óleo de coco e óleo de amendoim, Swamy et al. (2015) que testaram óleos de pinho, de cenoura, de rosa e de oliva, Indu et al. (2014) que usaram óleo de cedro; Udonkang et al. (2014) que avaliaram o óleo de palma, Ashitha (2018) que utilizou óleo de coco e óleo de palma, Carreira et al. (2019 que usaram óleo de rícino, Ravindran et al. (2018) que avaliaram o óleo palma, Tsamiya et al. (2021) que testaram óleos de cravo, amendoim e oliva e Akpulu et al. (2021) que avaliaram óleo de eucalipto.

Chandraker et al. (2018) usando óleo de coco e Tsamiya et al. (2021) testando óleos de cravo, de amendoim e de oliva, diafanizaram seus tecidos em temperatura ambiente, diferentes de Rasmussen et al. (1992) e Digala et al. (2017) que após a desidratação dos tecidos realizaram a clarificação em óleo de oliva a temperatura de 50oC, e óleo de coco a 60 oC, respectivamente, seguindo com à etapa de impregnação dos tecidos. O óleo de coco puro ou combinado com xilol, em nosso estudo, não divergiu do procedimento realizado apenas com o xileno; os óleos vegetais podem ser usados na rotina histológica e apresentam grande potencial como substituto do xilol na etapa de diafanização (Rasmussen et al., 1992; Indu et al., 2014; Udonkang et al., 2014; Swamy et al., 2015; Digala et al., 2017; Ashitha, 2018; Chandraker et al., 2018; Ravindran et al., 2018; Carreira et al., 2019; Akpulu et al., 2021; Tsamiya et al., 2021).

Apesar da pouca translucides dos tecidos, pudemos constatar que as lâminas obtidas pelo processamento com óleo de coco puro ou em associação com xilol foram semelhantes daquelas confeccionadas apenas com xilol, além de não ter interferido na fase seguinte, a de impregnação (banho de parafina na estufa) e emblocamento (Rasmussen et al., 1992; Premalatha et al., 2013; Chandraker et al., 2018; Akpulu et al., 2021). A adoção do óleo de coco extravirgem sem necessitar da associação com o xilol como diafanizador minimiza os riscos de problemas neurológicos, gastrointestinais, respiratórios, renais, cardiovasculares e dérmicos (United States, 2007; Cetesb, 2016; Cetesb, 2019) como é caso dos técnicos dos 
laboratórios que fazem uso desse solvente, assim como ao meio ambiente (Brasil, 2005).

Após a etapa de diafanização, em nosso trabalho, os órgãos foram transferidos para estufa a $650 \mathrm{C}$ para serem submetidos ao processo de impregnação, o tecido inicialmente é embebido em parafina líquida a 60-65oC e, posteriormente, incluso em um molde que também é preenchido com parafina. Após sólido, o bloco poderá ser cortado e as lâminas obtidas serem coradas (Tolosa et al., 2003; Timm, 2005; Nunes \& Cinsa, 2016; Camillo et al., 2017; Tsamiya et al., 2021). A realização adequada das fases de desidratação, clarificação e impregnação são fundamentais para que a confecção do bloco seja satisfatória, facilitando a microtomia (Nunes \& Cinsa, 2016). Em nosso estudo os órgãos também sofreram a etapa de impregnação em parafina em estufa histológica a $65 \mathrm{oC}$. Independentemente desse fato, podemos afirmar que o xilol possui, boa homogeneização com o óleo de coco e com a parafina, o que repercutiu na qualidade dos blocos, na microtomia e coloração dos tecidos.

Todos os grupos testados, em nosso estudo, apresentaram facilidade para o corte, embora o grupo IV, tratado apenas com óleo de coco, tenha apresentado maior facilidade. Isso é importante, pois a metodologia proposta, neste trabalho, não necessita do uso adicional de xilol para o sucesso desta etapa histológica; Rasmussen et al. (1992) afirmam que a miscibilidade do óleo de coco com a parafina é semelhante quando comparada ao xilol e que não existem diferenças nas etapas do processamento histológico; Chandraker et al. (2018) afirmam que apesar da boa homogeinização entre o óleo de coco com a parafina, quando comparada ao xilol, os blocos de parafina provenientes de óleo de coco apresentam dificuldades ao corte do micrótomos, sem comprometer, contudo, o resultado histológico.

As diferentes colorações utilizadas neste estudo (Hematoxilina/Eosina, Orceína/Hematoxilina, Tricrômico de Gomori e Hematoxilina Fosfotúngstica/Eosina não sofreram interferência devido ao uso do óleo de coco como clarificante. Segundo Nunez e Cinsa (2016) o processo de coloração é uma etapa importante, e fundamental visto que tinge os componentes teciduais e consequentemente permite a sua visualização. Para a realização da coloração dos tecidos é fundamental a retirada da parafina, que usualmente é precedida de banhos de xilol e álcool (Tolosa et al., 2003; Timm, 2005 e Nunez \& Cinsa, 2016). Em nosso estudo a retirada da parafina também foi realizada com xilol, assim com Udonkan et al. (2014) que utilizaram óleo de palma. Para essa etapa Rasmussen et al. (1992) retiraram a parafina das lâminas, com óleo de coco a 60 oC. Independentemente da metodologia usada a miscibilidade dos óleos com o xilol e a parafina é grande e não interfere na coloração com H/E (Rasmussen et al., 1992; Premalatha et al., 2013; Sermadi et al., 2014; Swamy et al., 2015; Indu et al., 2016; Ashitha, 2018; Chandraker et al., 2018; Abreu et al., 2019; Sermadi et al. 2019; Carreira et al. 2019 Tsamiya et al. 2021; Akpulu et al., 2021). Em relação a outras técnicas de tingimento histológico Rasmussen et al. (1992) não evidenciaram diferenças nas colorações histoquímica e imuno-histoquímica, fato corroborado por Sermadi et al. (2014) que constataram que a coloração com PAS (ácido periódico de Schiff) não é comprometida pelo uso do óleo de coco e nem com azeite (Sermadi et al., 2019).

Após a etapa de coloração as lâminas foram imersas em banhos de álcool, crescentes e em seguida foram aconcicionadas em estufa a $650 \mathrm{C}$ por 10 minutos, conforme proposto por Cazari et al. (2013) com adaptação, assim nesta etapa do processamento histológico não foi feito uso do xilol. Em relação a montagem das preparações histológicas, Rasmussen et al, 1992, utilizaram o Pertex® e Udonkang et al. (2014) usaram o (DPX - Distrene Plasticiser Xylene), ambas, são resinas sintéticas miscível em xilol. Na rotina histológica, a lâmina recem corada usualmente é submetida em banhos de álcool e xilol para em seguida ser adicionado sobre o tecido corado, uma resina líquida (veniz) micível em solvente e sobre ela uma lamínula de vidro (Timm, 2005; Paiva et al., 2006, Cazari et al., 2013), existem outros exemplos de vernizes, dentre os mais usados destacam-se Euparal ${ }^{\circledR}$, Entellan ${ }^{\circledR}$ e Permount ${ }^{\circledR}$ (Kraus \& Arduin apud Paiva et al., 2006) e o verniz vitral 500® (Paiva et al., 2006). 


\section{Conclusão}

O uso do óleo de coco é uma possibilidade segura, de baixo custo e capaz de minimizar o uso de xilol na rotina histológica, não causando comprometimento a morfologia dos tecidos e nem ao desenvolvimento das diferentes colorações, além de diminuir os riscos à saúde pública e ao meio ambiente. As divergências encontradas em nosso trabalho com algumas pesquisas que fizeram uso de óleos, mostra que a substituição do xileno ainda requer estudos, afinal a técnica em uso com este solvente e parafina é antiga, estando mundialmente disseminada e consolidada nos laboratórios de histologia e patologia, ainda assim, com diferenças pontuais entre os inúmeros centros de ensino e pesquisa. O presente estudo utilizou tecidos moles, assim como as inúmeras pesquisas consultadas na literatura, que subsidiaram esse trabalho, contudo, podemos comprovar que é possível substituir o xilol tendo o óleo de coco como solvente.

\section{Sugestões para trabalhos futuros}

Analisar como tecidos endurecidos, osso e dente, se comportam usando óleo de coco, uma vez que o processamento histológico desses requer, normalmente, uso de ácidos para remover os minerais e essa interação ácido-óleo-parafina carece de investigação.

\section{Referências}

Ashitha, A. S. (2018). Comparing the efficiency of coconut oil and palm oil with xylene as a clearing agent in conventional hematoxylin and eosin histopathological staining procedure. Dissertation. Departamento de Patologia Oral e Microbiologia - Universidade Médica do Tamil Nadu Dr. M.G.R. http://repository-tnmgrmu.ac.in/id/eprint/9841

Abreu, B. O.; Cunha, A. J. C.; Messias, I. M. O., et al. (2019). Óleo de coco, uma alternativa de diafanizador na técnica histológica, cap. 5:33-40. In: O estudo de anatomia simples e dinâmico, 4. Ponta Grossa, Athena Editora. doi.org/10.22533/at.ed.447192509

Akpulu, S. P., Hamman, W. O., Oladele, S. B. \& Ahmed, S. A. (2021). Comparative efficacy of Eucalyptus (Citrodora) oil and xylene as dewaxing and clearing agents in hematoxylin and eosin staining procedure. International Advanced Research Journal in Science, Engineering and Technology, 8(4): 122130. doi. org./10.17148/IARJSET.2021.8423

Araújo, G. S., Carvalho, R. H. R., \& Souza, E. M. B. D. (2009). Produção de biodisel a partir de óleo de coco (Cocos nucifera L.) Bruto. In: International Workshop: Advances in Cleaner Production. Anais eletrônicos.

Bancroft, J. D. \& Gamble, M. (2008). Theory and practice of histological techniques. Elsevier Health Sciences.

Bressan, R. T. Seabra Júnior, E, Dal Pozzo, D. M., Santos, R. F., \& Souza, S. N. M. (2017). Comparação dos parâmetros de qualidade e emissão de gases poluentes de biodiesel provindo de óleo de soja, coco e oliva. Acta Iguazu, 6(5): 239-246. doi.org/10.48075/actaiguaz.v6i5.18531

Camillo, C. S., Moura, S. A. B., Cardoso, C. C. N. D., \& Medeiros, F. B. (2019). Caderno de histologia texto e atlas. Natal: Edufrn. https://repositorio.ufrn.br/jspui/handle/123456789/23256?locale=en.

Carpiné, D. (2015). Desenvolvimento e caracterização de filme emulsionado biodegradável produzido a partir de proteína isolada de soja, óleo de coco e surfactantes naturais. 2015. 116 f. Tese (Doutorado) - Universidade Federal do Paraná. Curitiba.

Carreira, A., Neves, D., Morais, D., Lugovyy, D., Proença, H., Ladeira, C., et al. (2019). Óleo vegetal de rícino como diafanizador alternativo ao xileno no processamento de tecido animal. In: III Congresso Nacional de Ciências Biomédicas Laboratoriais, Escola Superior de Tecnologia da Saúde de Lisboa ESTeSL, 25 a 27 de outubro de 2019. https://repositorio.ipl.pt/handle/10400.21/12528? $\mathrm{mode}=$ full.

Cazari, V. R. da R., Pereira, T. R., Romera, A. M., Brandão, M. da C., Zelandi Filho, C. \& Favareto, A. P. A. (2013). Redução do uso do xilol na técnica de coloração hematoxilina e eosina. Colloquium Vitae, 5(2): 135-148. doi.org./10.5747/cv.2013.v005.n2.v084

Chandraker, R.; Rathod, V. C.; Chandraker, N. K., Pundir, S., Dixit, S. \& Desai, V. (2018). Comparison between xylene and coconut oil in tissue processing. Mod Med Lab J., 2(1): 96-99.

Cetesb (2016). Avaliação de benzeno; tolueno; o-xileno; m, p-xileno e etilbenzeno na atmosfera da estação de monitoramento de Pinheiros. https://cetesb.sp.gov.br/ar/wp-content/uploads/sites/28/2013/12/Relatorio-BTEX.pdf.

Cetesb (2021). Ficha de informação de produto químico. Companhia Ambiental do Estado de São Paulo. http://sistemasinter.cetesb.sp.gov.br/produtos/ficha_completa1.asp?consulta=XILENO\%20(META)\&cod=XILENO\%20(META)."

Costa, K. N. S., Pinheiro, I. O., Calazans, G. T. \& Nascimento, M. S. (2007). Avaliação dos riscos associados ao uso do xilol em laboratórios de anatomia

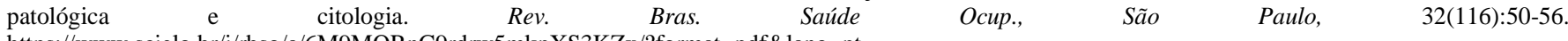
https://www.scielo.br/j/rbso/a/6M9MQRnC9rdrw5mkpXS3KZx/?format=pdf\&lang=pt 
Cuenca, M. A. G., Martins, C. R. \& Jesus Junior, L. A. (2021). A árvore do conhecimento. Empresa Brasileira de Pesquisa Agropecuária - Agência Embrapa de Informação Tecnológica - AGEITEC. https://www.agencia.cnptia.embrapa.br/ajuda.html.

Digala, P., Bollu, D., Karthicka C., Vincy, S.J., Selvam, R. \& Kandaswamy, S. (2017). Alternative to reduce occupational hazards for paramedical staffs in Histopathology Department. IOSR Journal of Pharmacy and Biological Sciences, 12(Issue 5, ver III): 05-12. https://doi.org./10.9790/3008-1205030512

De Souza Junior, J. C. (2010). Controle de qualidade em lâminas histológicas: importância da metodologia de H/E no diagnóstico médico. Monografia (Graduação) - Faculdades Integradas FAFIBE, Curso de Ciências Bebedouro. https://www.unifafibe.com.br/revistasonline/arquivos/revistabiologia/sumario/15/02032011082618.pdf

Do Nascimento, J. C., Cruz, I. L. S., Côrtes, P. P. R. \& Maleck, M. (2020). Técnicas histológicas adaptadas para tecidos de ratos. Revista de Saúde, 11(1):2528. https://doi.org/10.21727/rs.v11i1.1996

Embrapa - Empresa Brasileira de Pesquisa Agropecuária (2019). A Cultura do coqueiro. https://www.spo.cnptia.embrapa.br/conteudo?p_p_id=conteudoportlet_WAR_sistemasdeproducaolf6_1ga1ceportlet\&p_p_lifecycle=0\&p_p_state=normal\&p_ p_mode=view\&p_p_col_id=column-2\&p_p_col_count=1\&p_r_p_-76293187_sistemaProducaoId=7703\&p_r_p_-996514994_topicoId=7829.

Gartner, L. P. \& Hiatt, J. L. (2017). Tratado de Histologia em cores. (4a ed.). GEN Guanabara Koogan.

Gil, A. C. (2017). Como elaborar projetos de pesquisa. (6a ed.). Cortes

Hernandes, E., Schoffen, R. P. \& Conte, H. (2017). Xylene: features, risks, and management of waste. Brazilian Journal of Surgery and Clinical Research BJSCR, 17(2):68-73.

Indu, S., Ramesh, V., Indu, P. C., Prashad, K. V., Premalatha, B. \& Ramadoss, K. (2014). Comparative efficacy of cedarwood oil and xylene in hematoxylin and eosin staining procedures: An experimental study. Journal of Natural Science, Biology and Medicine, 5(2): 284-287. http://doi.org/ 10.4103/09769668.136167

Kraus, J.E. \& Arduin, M. (1997). Manual básico de métodos em morfologia vegetal. EDUR

Lima, E. B. C., Sousa, C. N. S., Meneses, L. N., \& et al (2015). Cocos nucifera (L.) (Arecaceae): A phytochemical and pharmacological review. Brazilian Journal of Medical and Biological Research, 48(11): 953-964, http://dx.doi.org/10.1590/1414-431X20154773

Michalant, J. 1988). Operações fundamentais da técnica histológica. In: Técnica histológica em anatomia patológica. Michalany, cap. II, p. $24-31$.

Mohammedsaleh, Z. (2014). The role of technical quality control in histology laboratories. Journal Of Cytology \&Histology, 05(05). http://doi.org/10.4172/2157-7099.1000264

Nunes, C. de S. \& Cinsa, L. A. (2016). Princípios do processamento histológico de rotina. Revista Interdisciplinar de Estudos Experimentais; 8(1): 31-40.

Ofusori, D. A., Ayoka, A. O., Adeeyo, O. A. \& Adewole, S. (2009). Mixture of kerosene and xylene: a contribution to clearing agents. International Journal of Morphology, 27(1): 211-218. http://dx.doi.org/10.4067/S0717-95022009000100036.

Paiva, J. G. A. de, Fank-de-Carvalho, S. M., Magalhães, M. P. \& Graciano-Ribeiro, D. (2006). Verniz vitral incolor 500â: uma alternativa de meio de montagem economicamente viável. Acta botânica brasileira; 20(2): 257-264.

Patraquim, A. C. (2015). Controlo de qualidade do processamento histológico em histotecnologia: a realidade de 12 hospitais portugueses. Dissertação Mestrado em Gestão e avaliação de tecnologias em saúde, Instituto Politécnico de Lisboa - Escola Superior de Tecnologia da Saúde de Lisboa.

Piculo, F. et al. (2014). Metodologia e equipamentos. In: Santos, S.L., et al. Guia ilustrado da morfologia do tecido uretral de ratas (pp. 13-26). São Paulo: Editora UNESP. https://static.scielo.org/scielobooks/m38sb/pdf/piculo-9788568334515.pdf

Premalatha, B. R., Patil, S., Rao, R. S. \& Indu, M. (2013). Mineral oil-a biofriendly substitute for xylene in deparaffinization: a novel method. The Journal of Contemporary. Dental Practice, 14(2):281-286. https://doi.org./10.5005/jp-journals-10024-1314

Rasmussen, B., Hjort, K., Mellerup, I., Sether, G., \& Christensen, N. (1992). Vegetable oils instead of xylene in tissue processing. Acta Pathol Microbio Immunol Scandinavica, 100(9):827-831.

Ravindran, R., Sruthi, A. K., Ameena, M. \& Harish, R. N. K. D. (2018). Bleached Palm Oil as a Bio-friendly Substitute for Xylene: A Comparative. Study. Oral and Maxillofacial Pathology Journal, 9(2):63-69. https://doi.org./10.5005. /jp-journals-10037-1132

Schwarz, F. W. (2017). Recuperação de solventes orgânicos de laboratório - uma alternativa econômica e ecologicamente adequada. 176 f. Dissertação de Mestrado - Universidade Federal do Rio Grande do Sul. Porto Alegre, 2017.

Sermadi, Z. M. W., Niranjan, K. C., Acharya, S., Prabhu, S. \& Killedar, S. (2019). Olive oil as xylene substitute. Journal of Oral Medicine, Oral Surgery, Oral Pathology and Oral Radiology, 5(2):46-51. https://doi.org/10.18231/j.jooo.2019.013

Sermadi, W., Prabhu, S., Acharya, S. \& Javali, S.B. (2014). Comparing the efficacy of coconut oil and xylene as a clearing agent in the histopathology laboratory. Journal of Oral and Maxillofacial Pathology,18:(Suppl 1):49-53. https://doi.org/10.4103/0973-029X.141348

Souza, D. S., Medrado, L. \& Gitirana, L. B. Histologia (2010). In: Molinário, E., Caputo, L. F. G., Amendoeira, M. R. R. (organizadores). Conceitos $e$ métodos para a formação de profissionais em laboratórios de saúde, 2. Rio de Janeiro: EPSJV; IOC; p. 43-88.

Sudeendra P, \& Acharya S. (2014). Comparing the efficacy of coconut oil and xylene as a clearing agent in the histopathology laboratory. Journal of Oral and Maxillofacial Pathology; 18(1): 4. 
Research, Society and Development, v. 11, n. 1, e5911124609, 2022

(CC BY 4.0) | ISSN 2525-3409 | DOI: http://dx.doi.org/10.33448/rsd-v11i1.24609

Swamy, S. K. R. G., Nandan, S. R. K., Kulkarni, P. G., Rao, T. M. \& Palakurthy, P. (2015). Bio-friendly alternatives for xylene - carrot oil, olive oil, pine oil, rose oil. Journal of Clinical and Diagnostic Research, 9(11): ZC16-ZC18. http://doi.org/ 10.7860/JCDR/2015/16384.6731

Timm, L. L. (2005). Técnicas rotineiras de preparação e análise de lâminas histológicas. Caderno La Salle XI; 2(1): 231-239.

Tolosa, E. M. C., Rodrigues, C. J., Behmer, O. A. \& Freitas Netto, A. G. (2003). Manual e técnicas para histologia normal e patológica. Barueri: Manole, 2003.

Udonkang, M., Eluwa, M., Ekanem, T. B., Asuquo, O. R., \& Akpantah, A. O. (2014). Bleached palm oil as substitute for xylene in histology. Journal of Physics and Chemistry of Solidis, 8(2): 8-14. https://www.arpapress.com/Volumes/JPCS/Vol8/JPCS_8_02.pdf

United States Department of Health and Human Services, Public Health Service - Agency for Toxic Substances and Disease Registry (2007). Toxicological profile for xylene. https://www.atsdr.cdc.gov/toxprofiles/tp71.pdf

Tsamiya, R. I., Muhammad, H.T., Mohammed, M.O., Abubakar, U., Mohammed, I., Muhammad, A. T., \& Ajayi, A. S. (2021). Journal of Medical Laboratory Science, 31(1):43-53. http://doi.org/10.5281/zenodo.4641412 